\title{
Viewpoint: \\ On rangeland carrying capacity
}

\author{
EMERY M. ROE
}

Author is executive director, Center for Sustainable Resource Development, College of Natural Resources, 112 Giannini Hall, University of California, Berkeley, Calif. 94720.

\begin{abstract}
A new typology shows that the notion of rangeland carrying capacity has considerable ambiguity even under conditions of high environmental certainty. When those environmental conditions are highly uncertain, rangeland carrying capacity must be reconceived as a Hahn equilibrium in order to be useful for rangeland development and management. A Hahn equilibrium is a state of affairs which does not cause decision-making agents to change the (meta-)theories which they hold or the (meta-)policies which they pursue in their decision making.
\end{abstract}

Key Words: carrying capacity, stocking rate, range management, uncertainty, Hahn equilibrium, knowledge generation

At a time when the planet's limited carrying capacity seems increasingly obvious, the rationale and measures of rangeland carrying capacity are increasingly criticized.

Say the carrying capacity recommendation is 1 livestock unit (equivalent to 450-500 kilograms) per 10 hectares in a dry range area-a not uncommon recommendation. It has been a fairly easy matter to throw doubt on that sort of stocking rate recommendation for some time (Roe and Fortmann 1982). First, dry areas may have key resources-such as localized swamps, marshes, and other spaces that enable a higher stock rate-so that the recommendation of 1 livestock unit per 10 hectares could never be a universal one, notwithstanding those countrywide maps stipulating livestock stocking rates that suggest otherwise. Second, the negative relationship between carrying capacity and "bush encroachment" (the number of shrubs and bushes) assumed by all those range scorecards belies the fact that browsing of such species forms a substantial portion of the livestock diet in many dry areas. Third, cattle grazed on extensive range do not average between 450 and $500 \mathrm{~kg}$ - in fact, they may be half that size, if not smaller, in parts of the Third World. Fourth, the carrying capacity concept all too often makes little short-term economic sense for many herders, and it is such economics which drive so much of the herder's stocking rate. Finally, the recent literature on rangeland disequilibrium models and state-and-transition models calls into question any specific measure of carrying capacity, whether the range is stocked or unstocked, managed or unmanaged (see also Scoones 1994).

\footnotetext{
Manuscript accepted 5 Oct. 1996.
}

Ideally, such objections can be taken into account for any individual carrying capacity estimate, by accepting that it has to be determined on a case-by-case basis in the field. Once you know the size of the grazing and browsing animals, and once you know the biomass production of the area, the pattern of livestock movements and watering, and so on, you can-so this argument goes-produce a site-specific carrying capacity estimate for the range area under consideration. Indeed, this is what is done in practice (Torell et al. 1991).

The case-by-case estimation of carrying capacity seems all the more sensible in light of the apparent obviousness of the the carrying capacity concept itself. Surely, there must be a finite limit to the population of any given area, indeed the planet as a whole, holding constant other factors such as technological change. Surely, you cannot pack livestock into a given rangeland, without at some point deteriorating that range demonstrably. Surely, biomass production is going down on rangelands precisely because carrying capacity has been exceeded for so long, even taking into account factors such as drought and climate change.

Such appeals will not do. Even under environmental conditions of great certainty, the notion of carrying capacity would still be ambiguous and confused. Moreover, since environmental conditions are highly uncertain for the dry rangelands of the world, current understanding of carrying capacity turns out to be all the more questionable. There is no workable, practical equation for carrying capacity, nor could there ever be. Fortunately, however, there is an alternative formulation of carrying capacity, which is considerably more realistic-if not more useful--than even the case-by-case variety.

\section{Methods and Results}

\section{Carrying Capacity Under Conditions of Certainty}

Fairly recent reviews of the notion of carrying capacity have concluded that it is very much a vague notion (e.g., Dhondt 1988). As Dhondt puts it, carrying capacity "has lost a precise meaning" as a term and instead "has been used with so many different meanings" that it is now irretrievably "a confusing concept." That said, it is important to underscore that the confusion would remain even if the meanings were precise and few in number. Assume in this section that the definition of carrying capacity as the maximum stocking rate possible without inducing damage to vegetation or related resources is clear and unambiguous. Ask yourself then, just what is this carrying capacity a case of? Of what is carrying capacity an instance? What kind of case are we analyzing when talking about "carrying capacity" in this way? 
Charles Ragin (1992) has developed a 2-by-2 typology that addresses the question of "What is a case?". The 2 dimensions are (1) whether the "cases" you are analyzing are taken to be empirical units in the real world or theoretical constructs that are a consequence of the theories you hold or analytic frameworks you use, and (2) whether these "cases," in turn, are taken to be specific in that they were developed during the course of your analysis or general in that they were pre-existing categories external to that analysis. Each of the resulting 4 types of cases can be seen at work in our understanding of rangeland carrying capacity:

(1) Cases as specific empirical units. Here, carrying capacity is to be found "out there" in reality. "In the first quadrant," according to Ragin, "researchers see cases [e.g., of rangeland carrying capacity] as empirically real and bounded, but specific. They Inust be identified and established as cases in the course of the research process" (Ragin 1992). Carrying capacity, according to Dhondt (1989), "is often used as if it were a property of the environment that can be measured" for any given specific habitat.

(2) Cases as general empirical units. Here, carrying capacity is an already known, objective category used in the objective world. "In the second quadrant, researchers also view cases [of rangeland carrying capacity] as empirically real and bounded, but feel no need to verify their existence or establish their empirical boundaries in the course of the research process. . These researchers usually base their case designations on existing definitions present in the research literatures," in Ragin's words (1992). The assumption in many range management textbooks, for instance, is that carrying capacity exists, whether or not one has procedure for delineating it precisely in empirical terms. Such a position is taken up by Dasmann (1964), among many others. "In all habitats we find a limitation on the number of game animals of any 1 species that can be maintained. This limitation is known as carrying capacity," adding, though, that "it is best to leave it [the notion of carrying capacity] to be used in a general rather than in a specific sense" (see Scarnecchia 1990 for a similar parallel between general and specific cases). ${ }^{2}$

(3) Cases as specific theoretical constructs. Here, what you interpret as carrying capacity depends on the interaction of the theories you hold and the research process you undertake. "Researchers in this quadrant see cases [of rangeland carrying capacity] as specific theoretical constructs which coalesce in the course of the research. Neither empirical nor given, they are gradually imposed on empirical evidence as they take shape in the course of the research. . Interaction between ideas and evidence results in a progressive refinement of the case conceived as a theorctical construct" (Ragin 1992). This interactive refinement is at work in the recognition that the concept of carrying capacity makes sense only when actual carrying capacity estimates are developed and worked through at specific sites. For example, in the view of Dhondt (1988), "if an equilibrium density [of animals] is reached, its exact value for any particular population depends on the interaction between the animals in the population

\footnotetext{
1Ragin is not the only one to focus on the questions, "What is this case of?". Rosenau and Durfee (1995) recommend that "one must be predisposed to ask about every event, every situation, or every unobserved phenomenon, 'Of what is it an instance?"' For another application of Ragin's typology, see Roe (1996).

Even where the focus of estimation is on specific carrying capacities, the estinates can be cast in general terms. In their textbook, Holechek et al. (1989) define carrying capaci ty as follows: "although actual stocking rates may vary considerably between years due to fluctuating forage conditions, grazing capacity is generally considered to be the average number of animals that a particular range will sustain over time".
}

and the environment in which the population lives. I feel therefore that speaking of a [concept like] "carrying capacity of the environment' should be avoided at all costs."

(4) Cases as general theoretical constructs. Here, carrying capacity is the result of the combined effort of range scientists, which shapes and constrains the way they undertake their science and research. "Finally, in the fourth quadrant," writes Ragin, "researchers see cases as general theoretical constructs, but nevertheless view these constructions as the product of collective scholarly work. . A researcher, for example, might conduct research on 'industrial societies' [or rangeland carrying capacity], recognizing that the assignment of empirical cases to this theoretical category is problematic and that the theoretical category itself exists primarily because of collective scholarly interest' (Ragin 1992). This type of carrying capacity is nost visible when members of the range science community question it and propose instead a new paradigm, such as "state and transition models" or "ecosystem resilience," or some other alternative theoretical construct.

Several results follow from this four-fold typology. First and foremost, we should not be surprised-nor, for that matter, even bothered-by the fact that very different types of "carrying capacity" are at work when people seek to manage stocking rates through setting rangeland carrying capacity limits. No 1 of the 4 "cases of carrying capacity" is a priori more useful than the others. More to the point, range managers and scientists cannot be expected to privilege just 1 type. There will always be textbooks, shifting paradigms, and interactive research processes-and unavoidably so. There is, in other words, no single true carrying capacity for any real system, because the real system in question is never just the range. ${ }^{3}$

Thus, it is wrong to believe that one is advancing knowledge simply by finding that, e.g., rangeland carrying capacity is more complex in the field than in a textbook like that of Stoddart, et al. (1975). All you are doing is confusing different types of carrying capacity. Nonetheless - and this is the crucial point-some confusion is inevitable, even under conditions of environmental certainty with precise and limited number of carrying capacity definitions, and it must be expected that range managers and scientists will from time to time talk at cross-purposes around the same table. These differing cases would remain even if resource managers and scientists did not entertain different theories. The problem is not that some experts subscribe to, e.g., range succession theory and others to state-and-transition models. Even if everyone subscribed to the same theory, the cases of rangeland carrying capacity would still differ as long as the experts did not agree on how to balance empirics and theory and the general and specific in the understanding and management of carrying capacity.

If carrying capacity is necessarily a constellation of different cases and conventions over just what carrying capacity is a case or instance of, then it should come as no surprise that managing carrying capacity is more likely to be effective when it legitimates these differing understandings rather than obscures, avoids, or forces us to choose among them. One such way to legitimate the co-existence of multiple cases of carrying capacity is to insist that the identification of rangeland carrying capacity is as much evolutionary as it is case-by-case: Range managers start with the

\footnotetext{
${ }^{3}$ Accordingly, a kind of systems thinking is required here, though its elements (textbooks, paradigms, interactive research processes) are considerably more open-ended (i.e., loosely-coupled and complexly interactive) than many systems thinkers would like.
} 
expectation that the carrying capacity is out there waiting to be identified, realize once in the field that there are problems in delineating carrying capacity features, later acknowledge that such problems arise in part because what is out there depends crucially on how what "it" is they are looking for is defined in the first place, and then end up in better understanding that what works best in any particular situation is a function of tailoring theory and practice to meet the specific objectives agreed upon in the identification of rangeland carrying capacity, again case by case.

In summation, even if carrying capacity were not vague and were easily definable and identifiable, there can never be 1 and only 1 definition and identification to be made. If carrying capacity is a moving target, it is always - repeat, always - moving several ways at once.

\section{Carrying Capacity Under Conditions of Uncertainty}

Unfortunately, environmental certainty with precise and few definitions is by no means guaranteed, thus problematizing the notion of carrying capacity even further. The above typology, for example, assumes that, even when cases of carrying capacity are multiple, advocates of each case are asking the right kinds of questions and getting the right kinds of answers for that case they call "carrying capacity". Uncertainty, in contrast, means there are times when we do not know what the right questions or answers are, let alone the "case" being analyzed. To see how this affects our conception of rangeland carrying capacity, consider the following thought experiment.

Assume that 2 groups, $i$ range experts and $j$ laypersons, are each characterized by a unique question-asking and answering function, $\mathrm{Qi}$ and $\mathrm{Qj}$, respectively,

$$
\begin{aligned}
& (Q \text {-function })_{i}=f\left(O B ; a_{1 i} Q_{1}, a_{2 i} Q_{2}, a_{3 i} Q_{3}, \ldots a_{n i} Q_{n}\right) \\
& (Q \text {-function })_{j}=f\left(O A ; a_{1 j} Q_{1}, a_{2 j} Q_{2}, a_{3 j} Q_{3}, \ldots a_{n j} Q_{n}\right)
\end{aligned}
$$

where $(\mathrm{OA}, \mathrm{OB})$ are constants (more in a moment), $\mathrm{Q}_{1} \ldots \mathrm{Q}_{\mathrm{n}}$ are the types of questions asked and answers given, and $\mathrm{a}_{1} \ldots \mathrm{a}_{\mathrm{n}}$ are the weights assigned to each type of question and answer in the Qfunction. As specified, the presence or absence of different types of questions and answers, along with the different weights assigned to each, set the 2 groups apart from each other. For schematic purposes, this multidimensional situation is reduced to a two-dimensional space, with our 2 homogeneous Q-functions drawn as in Figure $1 \mathrm{~A} .{ }^{4}$ Assume that the only questions and answers which matter to $\mathrm{i}$ experts and $\mathrm{j}$ laypersons are those about a given range's carrying capacity.

Those familiar with supply and demand analysis will interpret Figure $1 \mathrm{~A}$ as showing that, at $\mathrm{Q}_{\mathrm{e}}, \mathrm{i}$, and $\mathrm{j}$ are willing and able to ask $O Y$ questions and receive $O X$ answers. This would be incorrect. $Q_{\mathrm{e}}$ represents 1 point that generates 6 associated values, not just the 2 of $O Y$ and $O X$.

In this construction, $i$ and $j$ are each associated with 3 specific values at $Q_{e}$, namely, a specific number of questions that are answered, a specific number of questions that go unanswered, and a specific number of answers given to questions never really asked or that have already been answered. At $Q_{e}$ the $j$ laypersons, in order that their AY questions about range carrying capacity are satisfactorily answered, are willing to accept $\mathrm{OA}$ questions to go

4 The assumption of linearity is not mandatory; the positive slopes indicate only the necessary condition that the more questions asked the more answers expected.

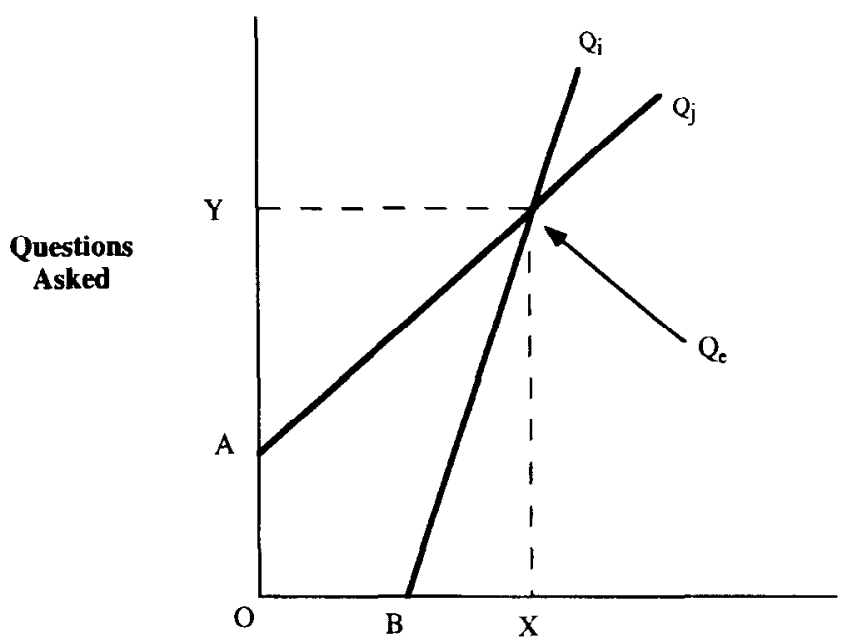

Questions Answered

Fig. 1A. Static two-person relationship between questions asked and answered.

unanswered by $i$ range experts and (OX - AY) answers to questions $\mathrm{i}$ mistakenly imputes to $\mathrm{j}$ or irrelevant answers by $\mathrm{i}$ to $\mathrm{j}$ 's AY questions. Similarly, at $Q_{\mathrm{e}}$ the $i$ experts are willing to accept, in order that $\mathrm{i}$ may ask and be answered correctly BX questions about carrying capacity, (OY - BX) of their questions to go unanswered and OB "answers," either imputed to but not actually asked by $\mathrm{i}$ or irrelevant answers to BX questions. Thus, the interchange as a whole between $\mathrm{i}$ range experts and $\mathrm{j}$ laypersons can be described by a level of "acceptable uncertainty" that $i$ and $j$ put up with, consisting of (OA + OY - BX) unanswered questions and $(\mathrm{OB}+\mathrm{OX}-\mathrm{AY})$ answers to questions never asked - both of which however may be crucial to the determination of the carrying capacity of the range in question.

For example, the questions $\mathrm{i}$ experts and $\mathrm{j}$ laypersons answer to each other's satisfaction, AY and BX, may reflect agreement by the 2 that indeed biomass of the range concerned has declined over time, that the stocking rates of livestock and human populations have increased on the rangeland, and that these populations have contributed to the decline in biomass production. The conclusion that stocking rates exceed the range's carrying capacity is, however, not warranted for several complicating reasons. First, there are the questions that have not been and may never be satisfactorily answered: e.g., to what extent have biomass changes been due to climate change unrelated to human and livestock use of the area under question? Second, there are the answers to questions never asked: e.g., air photos and satellite images, stored out of sight somewhere, may in fact show that biomass production has actually been increasing in the area as the area's population increased-something that has happened in several prominent cases recently (see, for example, Tiffen et al. 1994; Fairhead and Leach 1995).

Several results follow from the simple model. First, the most hanal yet imperative: What is actually going on in reality with respect to stocking rates and carrying capacity may or may not be reflected in any of the exchanges of questions and answers, whether those answers were asked for, given even if unasked for, or implied in the questions left unanswered. ${ }^{5}$ Less banal, the more 
groups involved in the question asking and answering exercise, the more likely that the actual conditions will be reflected in the answers given-if simply because the more groups, the wider the range of answers, other things being equal (remember, none of these values are 0 ). Simply put, the more people are uncertain in different ways, the more likely it is 1 or more of them is talking sense, other things being equal.

There is a more important result. One response to Figure $1 \mathrm{~A}$ is to insist that all this question asking and answering would eventually lead those concerned closer to the actual carrying capacity of the range in question. After all, so the argument goes, such questioning and answering could embody trial and error learning, where what would be learned should lead us, if not closer to the truth, then closer to knowing what is false. ${ }^{6}$ Thus, we would expect that over time (and again ceteris paribus) not only would the values of (AY and BX) change, but that the answers they reflect would eventually be driven closer to the true answer, namely, the range's actual carrying capacity.

But to what extent are the values of (AY and BX) likely to change? That depends in large part on whether or not $Q_{e}$ represents an equilibrium position in the 6 associated values. That is, would $i$ and $j$ accept any other set of values than those reflected in $Q_{e}$ ? Assume in Figure 1B that $j$ decides position $Q_{f}$ is preferred

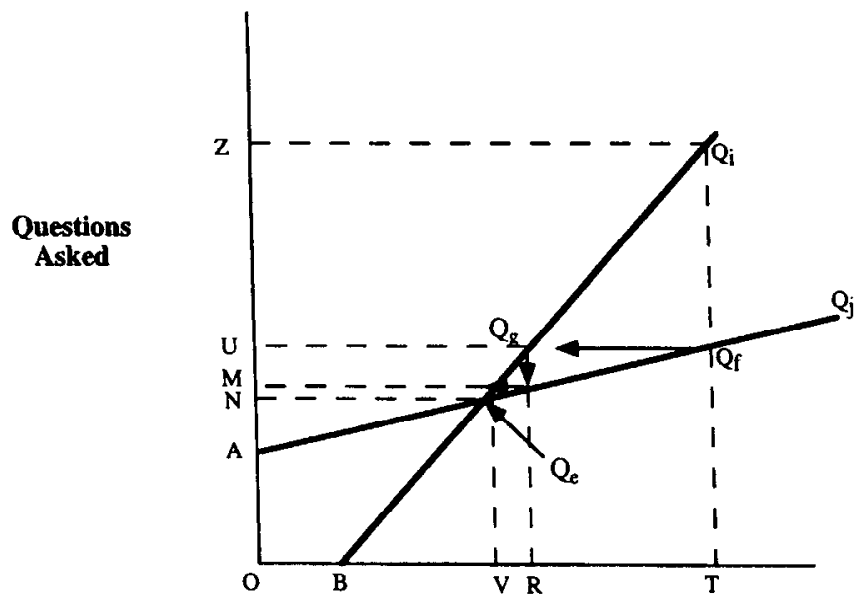

Questions Answered

Fig. 1B. Dynamic two-person relationship between questions asked and answered.

rather than $\mathrm{Q}_{\mathrm{e}}$. Remember, the quid pro quo operating here is "I will answer (some of) your questions, if you answer (some of) mine." Now, at $Q_{f} i$ could respond by generating the different set of values reflected at $Q_{i}$ or $Q_{g}$, namely, $i$ deciding that it wanted BT or BR of its questions answered. Say that $i$ chooses the $(U, R)$ mix by moving to $Q_{g}$. At $Q_{f}$ or $Q_{g}$, j wants $A U$ of its questions answered, but $i$ will only answer $j$ AM questions if $i$ is to get $B R$ questions correctly answered ( $\mathrm{i}$ gets BR questions answered whether $\mathrm{j}$ has $\mathrm{AU}$ or $\mathrm{AM}$ of its questions answered). Yet if $\mathrm{j}$ is

\footnotetext{
${ }^{5}$ As has long been pointed out, answers are implied in the sense that to ask a question entails one would know what would qualify as an answer to it.

${ }^{6}$ Put aside for the moment that what we would be moving to, even under conditions of environmental certainty, is a set of multiple cases of carrying capacity as in the previous section.
}

restricted to AM satisfactorily answered questions it will respond by allowing i BV (rather than BR) answered questions. However, if $i$ is restricted to $B V$ answered questions, it will in turn restrict $j$ to only AN (rather than AM) questions that it will answer. . .and so on until they arrive at $\mathrm{Q}_{\mathrm{e}}$. In short, there is strong pressure in this construction for both $i$ and $j$ to move to and stay at $Q_{e}$.

\section{Discussion and Conclusions}

\section{General}

As such, $Q_{e}$ is an excellent example of what has been called a "Hahn equilibrium". For the economist Frank Hahn, "an economy is in equilibrium when it generates messages which do not cause agents to change the theories which they hold or the policies which they pursue" (Hahn 1984). Accordingly, agents could be in equilibrium even when markets have not cleared or wages are rigid, as long as the theories and policies that are held allow for these disparities. The most interesting feature of a Hahn equilibrum, for our purposes, are those conditions that lead to stability in the agents' theories and policies. For Hahn "equilibrium states [are] those in which agents learn nothing new" (Hahn 1984). One important way in which this occurs is that environmental conditions may be so uncertain that there is nothing new for agents to learn, as in the case of $\mathrm{Q}_{\mathrm{e}}$ above.

Rather than being an instance where $Q_{e}$ and its associated values are moving over time closer to the 'true' value of the carrying capacity through constant trial and error (question asking and answering), $Q_{e}$ reflects instead those (admittedly arbitrary and local) theories and policies that allow agents to make decisions in the face of what seems to them to be continuing and intractable uncertainty. More formally, the policies and theories enable the agent to stabilize the assumptions for decision making under conditions of high uncertainty. Decisions have to be made, even when learning is not possible, and $\mathrm{Q}_{\mathrm{e}}$ reflects those theories and policies that allow the agents in question to decide, at least for a time.

That said, another economist, Brian Loabsy, suggests that we should

"add another level to Hahn's system, a level in which agents have theories about the generation of theories, and policies for the formulation of policies. Such meta-theories and metapolicies cannot be precisely specified, because it is logically impossible for the content of new knowledge to be predicted in advance or, what comes to the same thing, to be specified as the output, determinate, or probabilistic, of a well-defined process." (Loabsy 1991)

This suggestion has intuitive appeal, as all readers know of instances where local theories and policies do change, even when learning is not taking place nor causing those changes. Do such instances mean agents are out of equilibrium? Not necessarily, and herein lies this article's alternative formulation of rangeland carrying capacity. Even when local theories and policies are changing, the system in question still may be in equilibrium in the wider sense that the changes in question are guided by broader (meta-)theories and policies governing innovation in the knowledge base upon which the more local changes in theories and policies are founded. More formally, a system is in equilibrium when these meta-theories and meta-policies enable the agent to continue to make decisions under high uncertainty, even 
though his or her more local policies and theories governing decision making are themselves changing or in flux at the time.

If the notion of rangeland carrying capacity is to make any sense under conditions of high environmental uncertainty, it has to be at this meta-equilibrium level, where the notion of rangeland carrying capacity is, in effect, a meta-theory about how the capacity of a rangeland to carry a population changes over time, without however being able to predict what that carrying capacity will be in any specific instance or at any specific time. If this is so, then carrying capacity is really a theory of knowledge generation and change over a rangeland population and area.

In this view, the conception of carrying capacity is as much about biological and technological innovation as it is about biomass increases or decline in that area and population. Like all meta-theories that cannot predict the unknown in advance, it is more at home and on much sounder ground in identifying what makes for change (e.g., more livestock, changes in their technology) than it is in forecasting what is ahead for that area and that population. As a meta-theory of knowledge change in the face of high uncertainty (and to paraphrase Loabsy), carrying capacity has no business-repeat, no business-in specifying "outputs' such as all those estimates of a range's specific "carrying capacity." Such site-specific estimates are only warranted on the grounds of long experience and familiarity with the site concerned-which is simply another way of saying the range managers operate under considerably less uncertainty and have a tried and tested theory about what drives carrying capacity there. Moreover, it is that theory (and the more encompassing theories governing that local theory's change) which are the real objects of interest, not the specific estimates per se.

\section{Specific}

What specifically does carrying capacity as theory of knowledge generation look like as a Hahn meta-equilibrium? Many models are possible, but start with the oft-noted observation that more and more people, including range managers, knowingly make decisions on the basis of information which they also know will be obsolete by the time those decisions are implemented. ${ }^{8}$ Assume then the following relationships exist for any individual range manager concerned with carrying capacity (Fig. 2). Three variables are of interest for the range manager in question: the obsolescence of knowledge (ranging from 0 to high) he or she uses in dealing with carrying capacity issues (including those of stocking rates), the certainty of that knowledge (from 0 to high), and the urgency of the important decisions to be made by the manager on the basis of this knowledge (ranging as well from 0 to maximum). For expository purposes, the relationships are portrayed as in Figure 2. Note the "knowledge" in question has 2 parts: the manager's first-order, local policies and theories governing his or her movement along the curves and the secondorder, meta-policies and theories governing the shape of the curves in question. Moreover, this knowledge need not just be explicit, but could as well be tacit, as with ranchers who have long experience and familiarity with their range.

First, consider the relationship between the urgency of decision making about carrying capacity issues and the certainty of the

\footnotetext{
${ }^{8}$ While workable, practical definitions of carrying capacity are not possible, much more could be done in developing simple models of range manager decision making as is done here (see also Torell et al. 1991).
}

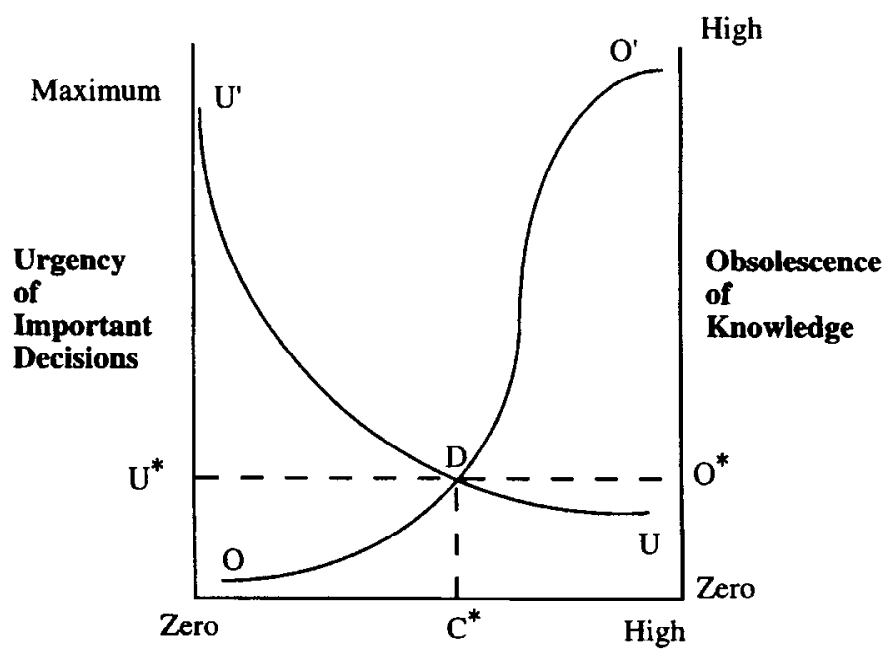

Certainty of Knowledge

Fig. 2. Manager response curves for obsolescence of knowledge, certainty of knowledge, and urgency of important decisions.

knowledge upon which that decision is made (UU' in Fig. 2). As drawn, the most urgent decisions are those for which little or no certain knowledge exists; on the other hand, important decisions always have some urging, no matter how certain the knowledge is on which they are based. Now consider the relationship between the obsolescence of knowledge and the certainty of that information (OO' in Fig. 2). As drawn, increased knowledge is rarely obsolete, when overall certainty is low; in these instances, what little knowledge the range manager gains typically has high timeliness and salience. On the other hand, there is a point at which the more certain the knowledge, the more likely it has become mundane, widely known, and of little further use. To put it another way, the more uncertain the information, the more that the decision to be made is an urgent one requiring up-to-date knowledge; in contrast, the more certain the knowledge, the more likely that this information has lost its currency. Again, the actual relationships vary empirically.

Where UU' and OO' cross yields 3 values of relevance for the individual decision maker: $\mathrm{U}^{*}, \mathrm{O}^{*}$, and $\mathrm{C}^{*}$. The 3 values reflect the only point where the range manager's sense of urgency intersects his or her perception of the obsolescence of the knowledge upon which his or her decision about carrying capacity issues is made. It is here (at D in Fig. 2) where the individual range manager is most comfortable in making carrying capacity decisions. In banal terms, the 3 values illustrate that the agent: avoids taking the most urgent carrying capacity decisions, recognizes that decisions have to be taken in the face of uncertainty, and acknowledges that some decisions are based on knowledge that is already well out-of-date.

Less banally, Figure 2 explains why range managers are always ready to convert policy decisions into administrative, bureaucratic ones (for more, see Roe 1996). Policy decisions are all too often those of high urgency, requiring timely knowledge in the face of extreme uncertainty. Diagrammatically, this situation reflects the decision space to the left of the intersection of UU' and $O O^{\prime}$ in Figure 2, particularly the widening gap between the 2 curves as they approach the axes. If the intersection point $D$ rep- 
resents both a preference on the part of the range manager and a model of what are the "right" kinds of decisions about carrying capacity, then there is enormous pressure to transform any decisions to the left of $\mathrm{D}$ into decisions that can be treated as if they were of $\mathrm{U}^{*}$ urgency, $\mathrm{C}^{*}$ certainty, and $\mathrm{O}^{*}$ obsolescence.

What is insufficiently recognized is the gap to the right of $\mathrm{D}$ in Figure 2. While the pressure to transform policy into bureaucracy has long been recognized, this same transformation ensures that the decisions to he taken are: still more urgent than others, less mundane than they could be, and based on knowledge that is more uncertain than other information-based decisions. If policy is all too easily turned into administration, then bureaucratizing issues of carrying capacity and stocking rates (e.g., into official scoring procedures and stocking maps) is in the same instant the way range managers resist trivializing those carrying capacity policies further.

Knowledge about carrying capacity is, in other words, generated in this model by the range manager's forging a pathway across a three-dimensional terrain of urgent decisions, uncertain knowledge, and obsolescent information relevant to what he or she takes to be the carrying capacity (and stocking rate) issues of interest. What makes this pathway possible depends on the ability of the range manager to ensure that relevant theories and policies can be transformed into bureaucratic and institutional methods and procedure for assessing the relevant issues of interest (see Joyce 1993). More formally, the manager's ability depends on the extent to which second-order meta-policies and meta-theories (namely, those that govern the shape of his or her OO' and UU' curves and their stability over time) allow for the creation of firstorder administrative procedures (namely, those more local theories and policies) under which the range manager can stabilize his or her day-to-day operations, even under great uncertainty. If stabilization of decision making does take place in this way, then $D$ in Figure 2 is a Hahn equilibrium.

In brief, one way to generate knowledge is to transform it into new modalities that seek to stabilize the assumptions for decision making in the face of admitted uncertainty, and the history of carrying capacity and stocking rate estimations is precisely just such a history of transformation, from textbooks in the classroom to scorecards in the field and from an eminently commonsensical idea in theory to transects and stocking rate maps on the ground. Moreover, this transformation will continue into the future, as long as uncertainty remains the key variable around which decision making pivots. Here too a mixing of categories and resulting confusion has been inevitable and should be expected to continue. It is not just that carrying capacity has become a confusing term; more practically, it will always be so, when the primary way we reduce uncertainty is to generate knowledge that cannot always be predicted in advance.

\section{Literature Cited}

Dasmann, R.F. 1964. Wildlife biology. J. Wiley and Sons. N.Y.

Dhondt, A.A. 1988. Carrying capacity: a confusing concept. Acta Oecologica: Oecologa Generalis. 9:337-346.

Fairhead, J. and M. Leach. 1995. False forest history, complicit social analysis-rethinking some West African environmental narratives. World Development. 23:1023-1036.

Hahn, F. 1984. Equilibrium and macroeconomics. Basil Blackwell. Oxford.
Holechek, J., R. Pieper, and C. Herbel. 1989. Range management: principles and practice. Prentice-Hall. Englewood Cliffs. N.J.

Joyce, L. 1993. The life cycle of the range condition concept. J. Range Manage. 46:132-138.

Loabsy, B. 1991. Equilibrium and evolution. Manchester University Press. Manchester and N.Y.

Ragin, C. 1992. Introduction: cases of 'What is a case?', p. 1-17. In: C. Ragin and $\mathrm{H}$. Becker, editors. What is a case?: exploring the foundations of social inquiry. Cambridge Univ. Press. Cambridge.

Roe, E. 1996. Why ecosystem management can't work without social science: an example from the California Spotted Northern Spotted Owl controversy. Environmental Manage. 20:667-674.

Roe, E. and L. Fortmann. 1982. Season and strategy: the changing organization of the rural water sector in Botswana. Special Series in Resource Management, Cornell University. Ithaca, N.Y.

Rosenau, J. and M. Durfee. 1995. Thinking theory thoroughly. Westview Press. Boulder, Colo.

Scarnecchia, D.L. 1990. Concepts of carrying capacity and substitution rations: a system viewpoint. J. of Range Manage. 43:553-555.

Scoones, I. 1994. Living with uncertainty: new directions for pastoral development in Africa. Overview paper prepared for the Workshop on New Directions in African Range Management and Policy, Woburn, UK, June 1993, International Institute for Environment and Development, London.

Stoddart, L., A. Smith, and T. Box. 1975. Range management. McGraw-Hill, N.Y.

Tiffen, M., M. Mortimore, and F. Gichuki. 1994. More people, less erosion. J. Wiley and Sons, N.Y.

Torell, L.A., K.S. Lyon, and E.B. Godfrey. 1991. Long-run versus short-run planning horizons and the rangcland stocking rate decision. Amer. J. of Agr. Econ. 73:795-807.

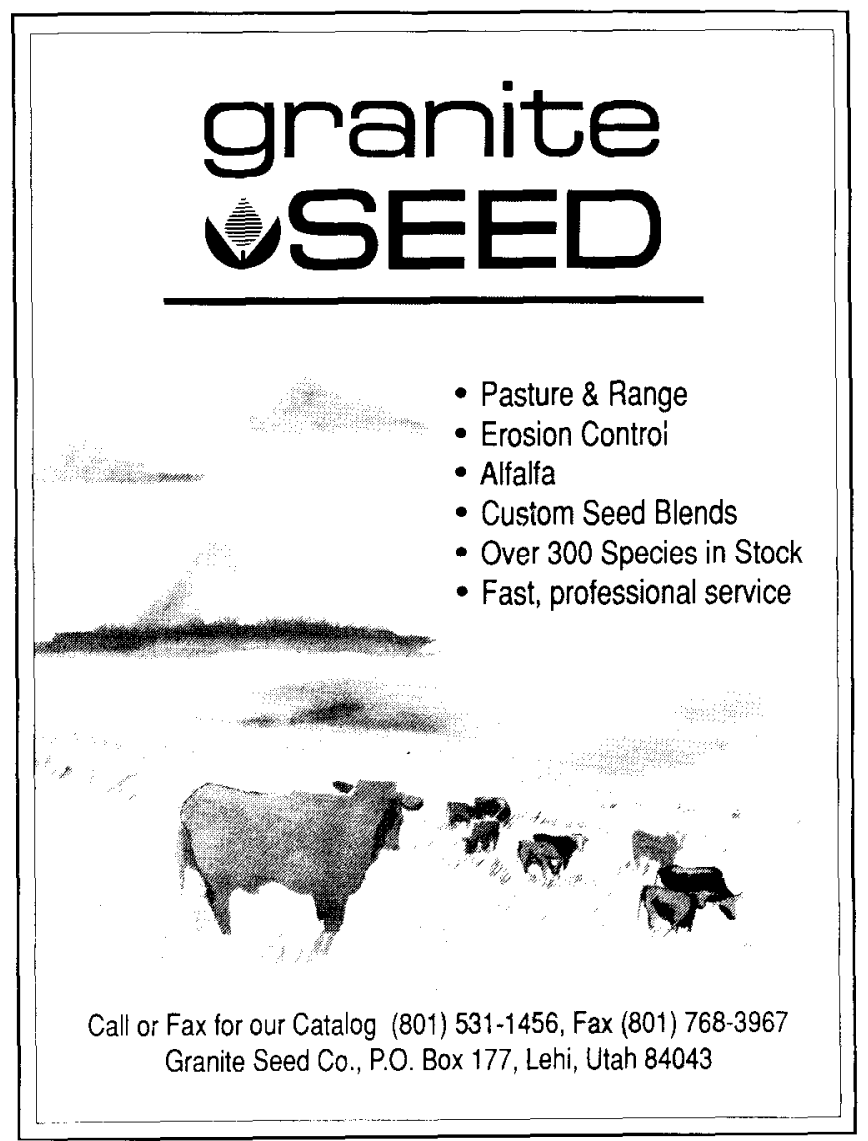

